\title{
Performance Autoethnography of a Philippine Music Concert
}

\author{
Leoncio P. Olobia* \\ leoncio.olobia@lnu.edu.ph \\ Leyte Normal University, Paterno Street, Tacloban City 6500, Philippines
}

\begin{abstract}
This performance autoethnography sought to dwell upon meanings in a musical concert: "Waray Gad La" featuring well-loved folksongs of Leyte and Samar islands in the Philippines. It expressed my folk sensibility in spite of my experimentations in form mixing various genres that would give rise to hybridization, transformation, self-identity, cycles of emotions, emancipation, and vulnerability as concepts revealed in the autoethnographic analysis. While they embodied cultural representations, this autoethnogrpahy focused mainly on musical aspects of performance foregrounding the themes identified.
\end{abstract}

The purpose of the study was to explore and analyze performances of "Waray Gad La" from a musical perspective using reflexivity in order to illuminate personal meanings within cultural praxis. Moreover, it was meant to unearth deep layers in interpretation of the featured performances mirrored with cultural resonances crossing over folkloric temperament layered with classical and new age nuances enriching sound poetry that would usher a new sound of age-old musical lore.

The study revealed that folksongs are not hackneyed expressions but with creative imagination, they can be recreated sensibly and powerfully. Grounded on the principle of universal musical expression, "Waray Gad La" epitomized experimentations in music structure unleashing energy in re-designing folksongs as artistic creations imbued with fresh ideas and emotions through meaningful associations as music rhetoric beyond persuasion.

Keywords: folksongs of Leyte and Samar; meanings in music; musical hybridization; performance autoethnography in music

\section{Introduction}

"Waray Gad La" was a musical concert conducted in Tacloban City, Philippines in October 16, 2021 featuring folksongs of Leyte and Samar islands in the Philippines, especially chosen and arranged based on association, recollection, and familiarity of the songs conveyed to me by my grandparents in my growing years. The concert encapsulated my folk sensibilities where I combined American, Asian, and European motifs that would describe cultural hybridization but was later viewed as a sacrosanct expression of individuality where music's universality glorified appropriation and fusion as grand narratives of my artistic license as the musical director of the program.

The purpose of the study was to explore and analyze performances of "Waray Gad La" from a musical perspective using reflexivity in order to illuminate personal meanings within cultural praxis. Moreover, it was meant to unearth deep layers in interpretation of the featured performances mirrored with cultural resonances crossing over folkloric temperament layered with classical and new age nuances enriching sound poetry that would usher a new sound of age-old musical lore. However, melodic enhancements and embellishments were not generally incorporated in the 
analysis as they belonged to the performers' creative pursuits, instead my analysis focused on thick descriptions of accompaniment layer altering traditional form, magnifying profound exhibition of musical wit and poetry.

In achieving depth of meanings, I reflected on the performance pieces as personal and cultural expressions, situating myself within cultural praxis while strengthening my understanding of music structure and cultural themes resonating to the society. Although my analysis centered on the concert's musical attributes, evocative storytelling touched upon identity expressions and historical signification, among other socio-cultural themes mirrored in the concert which should inspire other artists to draw upon inner meanings in creative endeavors.

Music autoethnography explores an intersection of autoethnographic approaches with studies of music (Bartleet \& Ellis, 2009). As we have discovered, music and autoethnography have much in common. At the heart of both is the desire to communicate engaging and personal tales, through music and words, which inspire audiences to react, reflect, and in many cases, reciprocate (Bartleet \& Ellis, 2009). Castro (2016) proposes the combination of performance and autoethnography as alternative methods to make use of musical scores. This approach strives for overcoming the duality body/mind in academic, musical research and comprises the embodied knowledge that arises from experience as a complementary epistemology to the corpus of knowledge about these instruments (Castro, 2016).

\section{Research Question}

1. What meanings were evoked in the concert: "Waray Gad La?"

\section{Research Approach}

\section{Methodology}

This qualitative study used performance autoethnography as a method of evocative and analytic inquiry.

\section{Locale and Period}

This study was conducted in Tacloban City, Philippines in a period of one week after the performance of "Waray Gad La" in October 16, 2021 at KBox Studios, Tacloban City.

\section{Data Collection and Analysis}

Qualitative data comprised the author's recollection of performances, fragments of memory of the concert. Observations, reflections, introspections and vignettes were coded to form concepts and themes significant to this performance autoethnography.

\section{Results and Discussions}

\section{Musical Hybridization}

"Waray Gad La" combines folk melodies and local expressions mixed with various American and European musical styles adding depth of artistic interpretation. Dwelling upon diatonic harmonies in folkloric articulations might be a hackneyed technique in vocal harmony, but, combined with interesting accompaniment features such as chord invertions, sweeping arpeggios in various intensity thicken the musical narrative. For instance, in "Kaisdaan", playful harmonic thirds and triads are interspersed with melodic nuances in certain episodes created to heighten complexity, emphasis, and texture. Moreover, accompaniment section is manicured with vibrant runs, tremolos, and trills using different percussive instruments mounted in layers within the structure emulating inner dialogue 
between counter-melodies as interwoven ideas.

"Kaisdaan exemplifies authentic expression rooted in my sensibility. With musical tools, this performance piece is a rich tapestry of form, structure and musicality creating a web of interlocking nuances."

The vignette mirrors a marriage between technique, musicality and cultural symbolism altogether developing a robust musical expression. In articulating accompaniment lines as structure, the use of classical technique such as dyadic and triadic harmonies borrowed from European form are juxtaposed with the same Spanish influenced danza tempo in slightly allegro motion indicate lively musical elucidation. In this incorporation of the European form, hybridization proves to be a bold gesture of authentic local sensibility because the foreign element becomes local and the intermingling of musical logic as a result of mixing creates coherence. In another performance, "Misay" exemplifies homophonic structure with nuances of music box accompaniment rendering the piece with light texture identified as a vocal etude with melodic lines swiftly crossing from low to high notes modulated to a slightly higher key to indicate climactic turns.

The epitome of cultural hybridization can be surfaced in "An Iroy nga Tuna" where melancholic melody is enhanced and somewhat replaced by a slow jazz tempo accentuated with improvisational lines from the saxophone which are instantaneous, vulnerable and engaging as one would experience upon listening to jazz music. In this paradoxical rendition of sentimental melody bearing nationalistic feeling, the mood is altered through reinterpretation of the musical form. This alteration of sensation as designed by the arranger is meant to divert emotional attachment away from sentimentality as hackneyed expression inherent in the song and the role of restructuring musical structure extends interpretation from the self to a larger colonial history of Westernization engulfing the song.

"With such reverberation of inner melancholy propounded by folk melodies in minor mode, focus is switched to something emotionally balanced interpretation with certain nuances of jazz syncopations altering melancholy to something celebratory and jovial."

The vignette clearly elucidates colonial tension espoused between patriotic themes and Western oracles with rhythmic blues grounding musical flow. Why such irony in the first place? The reason can be attributed to indeterminate meanings accruing to instrumental music where the absence of words allows for imaginative association of meanings to flow naturally. In other words, a listener's indulgent interpretation of melody, rhythm, texture and all other elements resides within one's emotional attachment to musical utterance. Such audacious association, engagement, and entrainment as clustering events deepen meaningful understanding of musical performance - all products of freedom in musical expression.

Because meanings are not final in music, its liberation is associated with cultural emancipation from a colonial history as a poignant reminder in "Iroy nga Tuna". However, with the performer's creative imagination, such poignant association is relieved, highlighted or even desecrated because music has the power to do all those things.

On a final note, hybridization as an audacious task of combining foreign element into local expression is not one but two-way process of dialogic interaction where mixing creates logical coherence. In the process of cultural confluence, the two distinct elements disappear as separate entities creating a universal flow of oneness. As such, all dichotomies as products of hybridization rest their signification in the creation of new expressions resulting from cultural mix. It does not matter if the form is European or American, what matters is the purity of the spirit in expressing deep emotions of the performer and how meanings are defined and constituted in the listener's end as indeterminate meanings. In this absorption, the form dissipates and emotional nourishment pervades.

How is the foregoing realized in musical arrangement? A musical arranger needs to be sensitive with cultural 
crossings but not to be limited just because a certain form is borrowed. Even with such argument, cultural borrowing in musical context is yet another level of discourse because European or American forms do not represent origins of such form in the first place. As melting pots of different migrating cultures, the same resounding voice of journeying sensibilities accrue to migrating people. For instance, rhythm as an element in music comes in various degrees, pulses and nuances relative to cultural background where it is highlighted, to wit: African syncopated rhythm as attached to multi-rhythmic language articulation in local African communities; Asian chant-like melodic utterances as embedded in meditative rituals for spiritual unification, among other examples illustrating pervasiveness of rhythmic pulses within cultural praxis.

As such, hybridization becomes a question in musical terms. It is a poignant question raised because it does not qualify objectively were a particular musical element locates in cultural history. There is only an approximation, a perceived generality, universality and totality of musical structure but because of music's indeterminate character to empower meanings inherently in multitude, subjective, and free, hybridization melts in oblivion. Where fusion had its way of elevating hybridization as a pinnacle of musical confluence in the past, that imprisoned notion exemplifies yet another victim of cultural misappropriation, such resonance is no longer fit in a world of interconnectedness.

\section{Musical Transformation}

Obliterating hybridization as a nuisance labeling, music finds its way in consciousness and emotion of both performer and listener as transformative resonance. Indeed, with emancipation ruling over, music's capacity to capture essence is the whole idea of performance signification as it transforms individuals in many ways. For one, a listener who is captivated by music's power has the audacity to modify beliefs and ideologies formed consciously or subconsciously while being transported or that music enables one's beliefs to create robust and resolute meanings associated even in packets of sound heard and absorbed sporadically. As such, meaningful associations can also be confined through fragments not necessarily as total experience. In musical language, a particular melodic section can form new levels of clustered meanings identified from past experience as a musical narrative in itself without dwelling upon totalities of melodic utterance. In simple words, one does not have to hear the whole song to enable to capture the essence the music wants to convey.

In "Kun Harapit nan Adlaw Matunod", a deep longingness surfaces throughout the song also expressed in music's minor mode as sad expression. However, even with such labeling, I managed to enthuse a feeling of celebration of pride in cultural expression enmeshed with grandioso lines most notable in the concluding section where a musical amalgamation is accentuated, a kind of triumph of individual expression beyond musical confinement. In other words, musical transformation elevates performance as an enlightenment, such liberation allowing creative energy to flow as a natural form. This can be physically mounted in the performer's inflections, sighs, gentle pauses or flamboyant bravados which add up to credibility and authority of performance. Such deep resonances can impact upon performance in small fragments or sections of the song without necessarily collecting large narratives of the whole song.

"As I played the accompaniment, I gazed upon the singers extending arms, raising fingers and pausing in certain phrases as they sang the song with emotions."

It must also be understood that musical transformation is the power to be affected by music where such power is inherently individual as music affects individually. As a personal realization, musical transformation builds its own signification sometimes without the need for others to further cement its musical effect. Expressed differently, musical transformation is a personal narrative of music's capacity to dwell upon individual interpretations that are unique, hence, not dependent upon social behavior to manifest its signification. 
In some cases, musical transformation creates a distinct character and semblance which can be apart from what the composer has intended. This instance makes interpretation to be a personal property of the performer not beholden upon the composer's will. The magic of emotional attachment, then, becomes glorified with the narratives of the arranger and performer as an entitled property. As such, transformation as a creative journey departs from its raw character, furthering and forming new levels of meanings in the artistic process.

This is the grandness of artistic transformation: its capacity to admonish logical alignment as a dictum of understanding becomes its highest goal. In musical experience, different meanings abound signifying that no definite associations should rule over. In the end, an individual's sense of personal glorification attests to music's meaning.

\section{The Self Within the Music}

"Waray Gad La" is a product of my creative indulgence as musical director and arranger of performance pieces mirroring my folk sensibilities. The choices are personal to me in the sense that they come from my grandparents' favorite list sang during casual moments whether in after-siesta interludes or nocturnal episodes with my grandfather playing the guitar.

"The songs epitomized a sense of self as I internalized every melody and lyrics. I realized that I was not only dwelling upon musical interludes but I was evolving as a sensitive person, sensitive to my history, my values defining myself."

Indeed, the vignette exemplifies self-expression as mirrored in melodic lines projecting deep-seated levels of identity formation. For one, soft tones from my grandmother's singing reverberates my soft spot as a calm person. In another light, dwelling upon visual images of musical tones highlights impressionistic nuances of my character as a musician who manages to understand tonality as color in music. In this regard, a great deal of sensitivity towards music-image confluence portrays a unity of meanings with the self at the center.

In my arrangement of "Dandansoy," melancholic melody is juxtaposed with images of linearity as a continuum where allegory abounds in fluidity and smoothness of musical line that has no definite ending marks. The song is treated as a cycle of placid emotion and the arrangement accentuates such tranquility. Even with vocal rests defined at the end of a verse, accompaniment flow manages to provide continuity as a single expression undisturbed in any form of discordance.

In another dimension of self-definition, vulnerability cogitates abruptness as a welcoming gesture. Off-guarded by any actuation that may prevail, the performer allows vulnerability to be a constructive insight, a creative impulse creating higher interpretive resonances in music. In this case, emotional readiness and unobstructed understanding of performance flow are two factors to be considered in meaningful utterance. In music, vulnerability opens new dimensions of artistic energy that may not be pre-determined, but, allows one to build new narratives of engagement because the self is emotionally and thoughtfully ready. The result, hence, becomes an outpouring of musical narratives thickening the process. Again, this attests to performance's emergent meanings as lived experience within an artist's milieu.

In translating the foregoing narratives to musical terms, vulnerability is epitomized in climactic turns such as dramatic renderings articulated in the beginning of "Lawiswis Kawayan" where cinematic sound is exhumed in the accompaniment with distinct rubato (holding back) tempo as emotive quality enriched with dark cello lines in the bass register, a rather unusual interpretation of a normally jovial rendition of the folksong. Such vulnerability allows the arranger and performer to create an instantaneous dialogue akin to mental telepathy in performance where moment-to-moment consonance of understanding creates a flow of thought and utterance. In the cinematic texture, 
visualization of sound transforms folklore in the realm of academic consciousness with profundity and subliminal seduction of some sort. Then, such dramatic prelude is disrupted upon the entrance of the standard $3 / 4$ rhythm in its usual temperament. However, virtuoso performance of intricate accompaniment lines is critical in transformation along with vocal prowess that needs to be endured from beginning to end. Towards this end, performance imbues critical elements in upholding creative messages with bravado rendition.

Corollary to self-identity is the articulation of cultural identity enmeshed in song lyrics, but as a musical drama, group identity requires deep recognition of musical symbols such as using diatonic harmonies so characteristic of folk music known not only locally but globally as well. In this situation, artistic imagination allows one to blend raw material with existing "package" of the musical designer with global influences so that a hybrid sound emanates as previously discussed. However, underneath musical experimentation is a cry for identity struggle which can be a tedious task to ameliorate, indeed. Musically, it is an assertion of the personal as part of a cultural consciousness embodying strong solidarity. A consciousness that dwells on historical forces enlightens a troubled self, yes it does, but in the grand musical celebration meanings tend to be repressed because of music's indeterminate character. This balances out strong sentiments asserted in the lyrics and music achieves different levels of sensations.

\section{Cycles of Emotions}

The musical trilogy composed of three folksongs: "Kun Harapit Nan Adlaw Matunod," "Masitas," and "Guin Hilom Ko" articulates complex cycles of emotions in putting together three separate songs as a round song layered upon each other in a musical dialogue. In musical analysis, the three songs within the same chordal structure creates linear harmonic passages construed as one song with melismatic ornamentations. This is clearly elucidated in the arranger's mind when the lyrics are not envisaged instead melodic linearity traverses through the medley.

In creating delicate balance between different emotive qualities, knowledge in timbre, dynamics and tonal color are important in restoring order such that sound magnification, for instance, of one episode renders the others as subordinating melodies even if they are independent tones in the first place. The effect is contrapuntal articulation of musical messages akin to conversational dialogue where speakers interrupt each other's talk instantaneously but the overall effect provides coherence. In such coherence, correct phrasing must be marked well so that the rise and fall of melodies, tonal dynamics and musical textures create an assemblage that is generally pleasing to the ears. It is in the gentle and robust interpretation of sound creating cycles of emotions where profound music is experienced by the performer and listener.

Inspired by an operatic scene with more than one performers singing together, this round song effect presents a unique quality of putting together three different songs lumped together as a coherent voice. In a way, it is a medley of songs but in many ways, it becomes an interspersing of different emotions from different nuances that when put together creates oneness.

What happens with individual character of each song? Musically, this can be resolved with the interplay of dynamics and phrasing placing emphasis on accented lines while 'repressing' sublime messages with softer tones. Such interplay of volume in sound deepens musical dialogue with 'listening tones' similar to speaker-listener cycle creating a tapestry of intricate lines in varying intensities. It must be realized that differing intensities provide complex layers of emotive quality in the sound.

In keeping with music's emotive power, essential meanings come into light with sensations created within musical nuances. In other words, sensation such as passion has powerful yet it can also possess indeterminate association of meanings of the sound but it sets the stage for emotional connection. When music captures an individual, there are moments of inexplicable passion and indulgence before an emotion ignites in a person. These are moments when one feels goosebumps after hearing a particular music. 


\section{Emancipation}

Performance autoethnography takes its pride in the liberation of the author's spirit as a declaration and expression of identity. While this is generally referred to as a cultural facet, emancipation is likewise rendered in musical terms when the arranger captures musical essence from various experimentations in form and style. For instance, in "Daw Nasusunog," sublime repetition of accompaniment phrases has a New Age effect popular with John Cage songs where rhetorical appeal through repetition magnifies specific phrases. This experimentation releases the arranger from constrictions defining folk genre which is more or less diatonic, direct and placid.

Emancipation in music once again departs from traditional norm as the artist is free to imbue energy forms in creating meanings. While this initiates freedom, the arranger indulges in a multitude of ways in creating meanings collected in space as the performer conveys meanings in singing. As energy forms, rhetorical meanings encapsulate inevitability, vulnerability and audacity through association as a natural form of expression so distinctly pronounced in any musical experience. As such, confluence of performer-music-audience elements provides thick descriptions of profound meanings which can be subconsciously determined. For instance, vulnerability as a rhetorical gesture allows for spontaneous interaction with the musical sound in an uncontrolled manner where the performer dwells upon intricate levels of unguarded emotions creating different nuances within the narrative. Similar with spontaneous creativity, vulnerability engulfs multi-level interpretations both positive and negative which need to be controlled and managed by the performer in order to diminish performance flaw. Within the positive domain, vulnerability enriches interpretation through the creation of musical ideas in improvisation while in the negative dimension, vulnerability can result in emotional indulgence so deep where meanings can be altered and disfigured in the process.

Overall, emancipation as a declaration of performance liberation catapults performance into a heightened sense of consciousness where obstructions are contained and expressions flow as natural energy form. Alongside musical mirroring, emancipation is without doubt a cultural affirmation of release from bondage, struggle and many forms of pain in human condition. As community expressions, folksongs empower commoners, the so-called backbone of society with culturally grounded themes of commonplace rituals, so ordinary that in many ways they can become lost in the narrative. However, with deep-seated freedom from historical struggles rightfully enjoyed by everyday people, a sense of exultation is endured and a wanton clamor for effervescent emancipation creates balance.

\section{Conclusion}

To answer the research question: "What meanings were evoked in the concert: "Waray Gad La?", this performance autoethnography illuminated my folk sensibility while experimenting on different sound using my influences in classical, pop, and jazz genres to mount various nuances of hybridization, musical transformation, identifying the self in music, indulging in cycles of emotions, emancipation, and vulnerability as concepts revealed in the autoethnographic analysis. While these themes embodied cultural representations, this autoethnogrpahy focused on the musical aspects of various performance foregrounding the concepts I had identified.

In totality, performance pieces in the concert elevated folksongs as artistic creations where I possessed artistic license to re-create age-old folksongs with fresh ideas inviting new emotional connections through meanings association within rhetorical realm. Thus, rhetoric in performance exemplified creation of meanings rendering traditional rhetoric as persuasion anachronistic.

\section{References:}

Bartleet, B. \& Ellis, C. (2009). Music Autoethnographies: Making Autoethnography Sing/Making Music Personal. Australian Academic Press. Retrieved from www.researchgate.net. 
Castro, RMV (2016). Performance and Autoethnography in Historical Musicology - SciELO. Retrieved from www.scielo.br.

Ellis, C., Adams, T., \& Bochner, P. (2010). Autoethnography: An Overview. Forum Qualitative Sozial Forshcung. Retrieved from www.qualitative-research.net.

Mabuhay Singers (1996). Lubi-Lubi \& Other Waray Folksongs Album. Retrieved from www.songslyrics.com.

Sotnas, A. (2015). Waray Songs and Poetry. Retrieved from www.scribd.com. 